\title{
KARAKTERISASI IMPEDANSI LAPISAN TIPIS ZnS:Mn YANG DIBUAT DENGAN CO-EVAPORASI ZnS DAN Mn
}

\author{
Stepanus Sahala $\mathbf{S}$ \\ Jurusan PMIPA, Prodi Pend. Fisika FKIP \\ Universitas Tanjungpura Pontianak
}

\begin{abstract}
The aim of this research is to characterize impedance, capasitance and relative permitivity of the characteristics of electric thin film $\mathrm{ZnS}$ and ZnS:Mn. This research was started from making thin film with different deposition speed and with thermal co-evaporation method in vakum tubes. The estimation is the characteristics of thin film $\mathrm{ZnS}$ impedance and ZnS:Mn was done outside this vacum with various frequency between thousaund to million hertzs, with different deposition speed and the same thickness. Defining impedance of $\mathrm{ZnS}$ thin film wich the most optimal frequency would influence capasitance and relative permittivity of the thin film on the characteristics of the electricity. Besides, capasitance and resitance values of ZnS:Mn thin film would change if given different Mn portion on that thin film. From the result of the research, it could be identified as follows. On the area of the thousand to ten thousand Hertz, it was know is that relative permitivity/constante static dielectrics $K_{(0)} \mathrm{ZnS}: \mathrm{Mn}$ thin film was not the frequency function that it could be regarded as constant like $K_{(o)}=10$. The price of capasitance ZnS:Mn was increasing with less $\mathrm{Mn}$ amount in that thin film. The price of ZnS:Mn electric resitance is reduced with less Mn amount on that thin film.
\end{abstract}

Key words: Impedance, thin film ZnS:Mn, co-evaporation.

Perkembangan penerapan lapisan tipis serta pengaruhnya semakin besar terhadap kehiduan manusia, membuat para ilmuwan berusaha terus untuk meneliti sifat-sifat material ataupun kegunaannya. Minat terhadap teknologi elektronik dan optoelektronik yang berkembang tidak hanya pada peningkatan sifatsifat material intrisik tetapi juga pada material ekstrinsik. Sifat material ekstrinsik sangat mudah dikembangkan untuk memperoleh material yang memiliki transparansi dan resistivitas listrik yang tinggi secara simultan.
Teknologi pelapisan semakin berkembang seiring dengan penggunaannya terutama dibidang optik dan mikroelektronik. Lapisan tipis seng sulfida ( $\mathrm{ZnS})$ merupakan salah satu jenis material yang banyak digunakan baik dalam perangkat elektronik maupun dalam optik. Salah satu aplikasinya adalah sebagai bahan fosfor pada perangkat elektroluminesensi Thin Film Electrolumicence (TFEL) yang menggunakan medan listrik sebagai pembangkit cahaya non termal (Ono, 1993, Kim, et al, 2000). ZnS pada medan rendah merupakan material dielektrik yang baik dengan 
resistivitas mencapai $10^{14} \mathrm{Ohm} \mathrm{cm}$ dan pada medan listrik di atas harga 1 MV $\mathrm{cm}^{-1}$ arus yang melewati material ini akan naik secara eksponensial dengan naiknya tegangan yang diberikan (Bringuer, 1994, Marc Beale, 1993).

$\mathrm{ZnS}$ yang di doop dengan $\mathrm{Mn}$ merupakan material elektroluminesensi yang hingga dewasa ini banyak diteliti (Lee and Pueng, 1993, Okamoto, et al, 1989, Charreire, et al, 1993). dan sudah dipergunakan secara komersial dalam AC Thin Film Electrolumicence (ACTFEL) (Xian, et al, 1994, Gordon, 2000). Piranti TFEL ZnS:Mn mendapat perhatian besar karena memiliki keunggulan yaitu ; tahan getaran dan perubahan temperatur karena semuanya terbuat dari bahan padat, mempunyai daya resolusi tinggi, hanya memerlukan daya rendah, tipis dan ringan, tingkat kecermelangannya yang sangat tinggi, umurnya panjang, dan Brigthness Voltage Response yang cepat serta Emission Effciency (EL) yang cukup tinggi (Higuchi, et al, 1988, Fuh, et al, 1987, Horakazu Izumi, et al, 2002).

Pada dasarnya piranti TFEL ZnS:Mn terdiri dari atas dua lapis konduktor yang mengapit lapisan fosfor setebal $5000-10000 \AA$ dan merupakan bagian utama yang berfungsi sebagai penghasil cahaya, jika lapisan tipis tersebut berada pada medan listrik dan lapisan tipis ZnS:Mn ini dapat dioperasikan dengan sumber arus ac atau dc (Lewis and Paine, 2000). Penelitian yang banyak dilakukan sekarang ini, difokuskan pada konfigurasi ac Thin Film Electrolumicence (ACTFEL) dibandingkan dengan $d c$ Thin Film
Electrolumicence (DCTFEL), karena DCTFEL mempunyai keterbatasan konfigurasi yaitu umur operasinya yang pendek. (Jones, 1988). Keadaan ini terutama disebabkan karena terjadinya Highly Localized Destructive Breakdown yang secara bertahap akan menpercepat rusaknya lapisan tipis tersebut (Freman, et al, 2000).

Dalam penelitian ini dilakukan dalam bentuk konfigurasi ac Thin Film Elektrolumicence. Dengan membuat dua konfigurasi ACTFEL yang sama dalam material kontaknya dan kemudian mengukur tegangan pada lapisan tipis $\mathrm{ZnS}$ dan $\mathrm{ZnS}: \mathrm{Mn}$ serta melihat karakterisasi impedansi sebagai fungsi frekuensi diharapkan akan diperoleh gambaran tentang pengaruh frekuensi yang bervariasi terhadap impedansi dan dimungkinkan juga diperoleh gambaran tentang laju pelapisan/deposisi rate yang berbedabeda dengan ketebalan lapisan tipis yang tetap terhadap impedansi dari lapisan tipis yang dibuat. Demikian pula dari hubungan ini dapat diperoleh besarnya kapasitansi dan permitivitas relatif dari lapisan tipis tersebut.

Pembuatan piranti lapisan tipis $\mathrm{ZnS}$ dilakukan dengan metode evaporasi termal, sedangkan lapisan tipis $\mathrm{ZnS}: \mathrm{Mn}$ dideposisi dengan coevaporasi termal, dimana dilakukan evaporasi simultan $\mathrm{ZnS}$ dan $\mathrm{Mn}$ dengan menggunakan dua sumber yang terpisah di dalam bejana vakum selama proses deposisi. Kemudian lapisan tipis tersebut dikontakkan dengan lapisan metal aluminium.

Tujuan Penelitian ini adalah memperoleh gambaran tentang pengaruh frekuensi yang bervariasi 
terhadap impedansi pada lapisan tipis $\mathrm{ZnS}$ dan ZnS:Mn, laju pelapisan/deposisi rate yang berbeda dengan ketebalan terhadap impedansi lapisan tipis $\mathrm{ZnS}$ dan $\mathrm{ZnS}: \mathrm{Mn}$ yang dibuat dengan evaporasi termal, hubungan perubahan impedansi terhadap kapasitansi dan permitivitas relatif dari lapisan tipis $\mathrm{ZnS}$ dan $\mathrm{ZnS}$ Mn tersebut dan memberi informasi karakteristik impedansi, kapasitansi dan permitivitas relatif lapisan tipis $\mathrm{ZnS}$ dan ZnS:Mn bagi peningkatan teknologi bidang optik dan bidang mikroelektronik.

\section{Metode}

1. Bahan dan Peralatan

Material pelapis yang digunakan terdiri seng sulfida $(\mathrm{ZnS})$ berbentuk bulk dari Leybold-Heraeus dengan kemurnian 99,9\%, dan sebagai bahan co-evaporasi dipergunakan mangan (Mn) dari Leybold-Heraeus. Sedangkan sebagai material kontak lapisan tipis dipergunakan aluminium (Al) berbentuk kawat dengan kemurnian 99,99\% juga diperoleh dari Leybold Materials. Substrat yang akan dilapisi berupa kaca praperat berukuran 76 x 26 x.1 mm. Untuk memperoleh pola pelapisan yang diinginkan, dipergunakan suatu cetakan (masker) yang dibuat dari aluminium dan diletakkan pada kaca preparat selama proses pelapisan berlangsung.

Lapisan tipis dibuat dengan menggunakan Universal Vacuum Coater dari Leybold-Heraeus model UNIVEX 450, yang terdiri dari pompa rotari TRIVAC D65B, pompa turbo TURBOTRONIK NT 150/360, perangkat glow discharge
CONTRASTER C 2000, dan alat pengukur tekanan COMBIVAC IT 230. Ketebalan lapisan diukur dengan INFICON model XTC yang dilengkapi dengan kristal Quartz Silver sebagai sensor. Pada proses pelapisan, material bulk $\mathrm{ZnS}$ diletakkan pada wadah Molibdenum (Mo) berbentuk kapal yang dipasang pada sumber evaporasi termal AS 052, dan Al diletakkan pada wadah wolfram (W) berbentuk kapal yang dipasang pada AS 052. Tahap berikutnya adalah pengukuran impedansi (resistansi) ac. Untuk melihat pengaruh frekuensi terhadap lapisan tipis yang dibuat, digunakan sinyal generator arus bolak-balik dari TOELLNER model TOE7704 yang memiliki daerah kerja dari $1 \mathrm{MHz}$ hingga 12 MHz.Sebagai pengukur tegangan digunakan osiloskop dengan dua saluran (channel) dari HAMEG model HM408 yang memiliki daerah kerja hingga $40 \mathrm{MHz}$.

2. Pengambilan Data

Sampel yang telah jadi kemudian diukur impedansinya dengan susunan rangkaian seperti pada Gambar 1. Untuk mendapatkan harga arus yang melalui sampel, digunakan hambatan sebesar $47 \Omega$ yang diseri dengan sampel. Dengan mengetahui harga tegangan pada hambatan tersebut, maka harga arus yang melalui sampel dapat dicari dengan persamaan Hukum Ohm, yaitu : $\mathrm{i}=\frac{V_{47 \Omega}}{R}$.

Setelah harga arus diketahui, maka harga impedansi (resistansi) ac dapat dicari dengan:

$\mathrm{Z}=\frac{V_{\text {sampel }}}{i}$ 


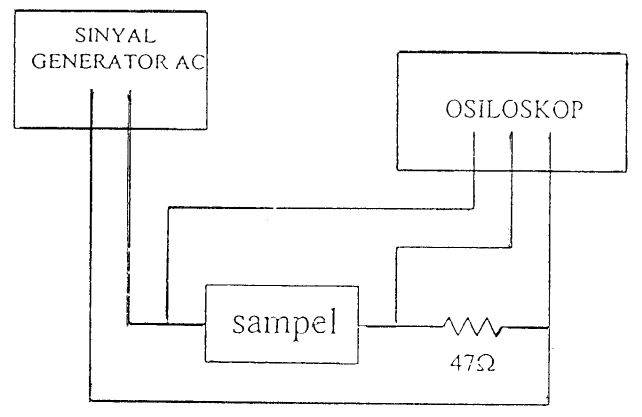

Gambar 1. Bentuk rangkaian pengukur impedansi lapisan tipis

\section{Hasil dan Pembahasan}

1. Pengukuran Impedansi Listrik/AC Lapisan Tipis $\mathrm{ZnS}$ dan $\mathrm{ZnS}: \mathrm{Mn}$

Dari pengukuran yang dilakukan dengan menggunakan rangkaian ac, diperoleh data mengenai frekuensi dan tegangan. Tegangan pada sampel dibuat tetap 1 volt. Tegangan yang terukur pada resistor $47 \quad \Omega$ yang dihubungkan seri dengan sampel akan dipergunakan untuk mengetahui harga arus pada sampel. Harga frekuensi divariasikan dari ribuan hingga jutaan hertz dengan menggunakan signal generator. Harga tegangan yang terukur hanya diambil dari satu dan penambahan setengah pada frekuensi yang ditampilkan. Sedangkan frekuensi lainnya tidak ditampilkan pada tabel hasil pengukuran karena pada jangkauan frekuensi tersebut, harga tegangannya sama dengan yang terukur pada frekuensi sebelumnya.

2. Karakteristik Pengukuran Impedansi ac Lapisan Tipis $\mathrm{ZnS}$ dan $\mathrm{ZnS}: \mathrm{Mn}$

Dari analisis data penelitian ini diperoleh bahwa secara umum frekuensi ribuan sampai jutaan ribu Herzt untuk laju deposisi $10 \AA /$ s , $20 \AA / \mathrm{s}, 30 \AA / \mathrm{s}$ dan $40 \AA \mathrm{A} / \mathrm{s}$ dengan ketebalan rata-rata $700 \AA$ lapisan tipis (thin film) $\mathrm{ZnS}$ dan $\mathrm{ZnS}: \mathrm{Mn}$, harga impedansinya mengalami perubahan terhadap frekuensi. Makin besar frekuensi kerja pada thin film tersebut, makin kecil harga impedansi listriknya. Pada kasus seperti ini, kemungkinan butir-butir (graingrain) yang terbentuk tidak padat /rapat sehingga ruangan antara grain-grain tersebut dipisahkan oleh udara dan film ini berbentuk seperti pulau-pulau sehingga membuat bagian film-film yang terbentuk berfungsi sebagai kapasitor. Hal ini pernah dikemukakan pada suatu penelitian mengenai paduan $\mathrm{Ni}-\mathrm{Cr} 9$ (Anonimous, 1994). Jika dianggap bahwa susunan lapisan tipis $\mathrm{Al}: \mathrm{ZnS} / \mathrm{ZnS}: \mathrm{Mn}: \mathrm{Al}$ merupakan suatu kapasitor yang terhubung secara parallel dengan resistor, maka secara model rangkaian lapisan tipis seperti ini ekivalen dengan sebuah resistor (R) yang terhubung parallel dengan sebuah kapasitor (C).

Dari model rangkaian parallel RC ini, pada daerah frekuensi $1 \mathrm{KHz}$ perubahan impedansi lapisam tipis ini menunjukkan bahwa sedang terjadi pengsian pada $\mathrm{C}$ dan discharge 
pada R. hal ini terjadi karena harga frekuensi yang diberikan semakin berkurang dan arus listrik mulai dapat melewati bagaian kapasitif dari model rangkaian tersebut.untuk daerah frekuensi ini C masih diangap konstan terhadap frekuensi, karena konstante dielektrik (K) belum merupakan fungsi frekuensi (Anderson, et al , 1985).

Pada daerah frekuensi berikutnya yaitu antara $10 \mathrm{KHz}$ hingga di bawah sedikit $1 \mathrm{Mhz}$, penurunan impedansi yang terjadi tidak setajam pada daerah frekuensi sebelumnya. Hal ini disebabkan material dielektrik (lapisan tipis $\mathrm{ZnS}$ dan $\mathrm{ZnS}: \mathrm{Mn}$ ) mulai tidak mampu mengantisipasi perubahan arah medan listrik yang berlangsung makin cepat akibat frekuensi yang diberikan makin besar. Bahkan pada frekuensi yang lebih tinggi, yaitu di atas $1 \mathrm{Mhz}$ terjadi proses relaksasi yang menunjukkan bahwa material dielektrik ini benar-benar tidak mampu lagi mengantisipasi perubahan arah medan listrik yang berlangsung sangat cepat sehingga terjadi kenaikan impedansi lapisan tipis $\mathrm{ZnS}$ dan $\mathrm{ZnS}: \mathrm{Mn}$.

3. Perhitungan Kapasitansi Dan Resistansi Lapisan Tipis ZnS dan $\mathrm{ZnS}: \mathrm{Mn}$

Untuk menghitung

kapasitansi dan resistansi lapisan tipis $\mathrm{ZnS}$ dan $\mathrm{ZnS}: \mathrm{Mn}$ ini digunakan metode kuadrat terkecil dengan menggunakan persamaan:

$\frac{1}{Z^{2}}=\omega^{2} C^{2}+\frac{1}{R^{2}}$.

Dengan persamaan ini dapat dibuat/dihitung kurva yang mendekati data-data hasil eksperimen, untuk menentukan perkiraan harga kapasitif $\mathrm{C}$ dari kapasitor dan resistansi $\mathrm{R}$ yang terbentuk pada lapisan tipis tersebut. Perhitungan dilakukan dengan menggunakan data-data pada frekuensi antara $1 \mathrm{KHz}$ hingga $10 \mathrm{Khz}$.

Dari metode kuadrat terkecil tersebut, diperoleh data kapasitansi dan resistansi untuk masing-masing sampel sebagaimana diperlihatkan pada Tabel 1.

Tabel 1. Hasil perhitungan kapasitansi dan resistansi dari lapisan tipis ZnS:Mn dengan kadar Mn bervariasi.

\begin{tabular}{|c|c|c|c|c|c|c|}
\hline No. & No. & $\begin{array}{c}\text { Laju } \\
\text { Deposisi }\end{array}$ & $\begin{array}{c}\text { Kadar } \\
\text { Mn }\end{array}$ & Kapasitansi & Resistansi & $\begin{array}{c}\text { Konstante } \\
\text { Dielektrikum }\end{array}$ \\
\hline & Sampel & $(\mathbf{A} / \mathbf{s})$ & $(\%)$ & $(\mathbf{n F})$ & $(\mathrm{K} \Omega)$ & (K) \\
\hline 1 & 4 & 40 & 0 & 14,14 & 7,07 & 14,25 \\
\hline 2 & 5 & 40 & 0,025 & 14,11 & 7,11 & 14,22 \\
\hline 3 & 6 & 30 & 0,03 & 14 & 7,12 & 14,11 \\
\hline 4 & 7 & 20 & 0,05 & 13,9 & 7,16 & 13,95 \\
\hline 5 & 8 & 10 & 0,1 & 13,8 & 7,2 & 13,85 \\
\hline
\end{tabular}

Dari Tabel 1 terlihat bahwa penambahan kadar $\mathrm{Mn}$ pada lapisan tipis $\mathrm{ZnS}: \mathrm{Mn}$ ternyata menunjukkan adanya perubahan nilai kapasitansi dengan perkataan lain semakin kecil kadar Mn yang diberikan maka semakin bertambah nilai dari kapasitansi 
lapisan tipis tersebut. Demikian pula halnya dengan resistansi dari lapisan tipis tersebut, seperti pernah dikemukakan pada suatu penelitian pengaruh kondisi saat pembentukan lapisan tipis $\mathrm{Cu}-\mathrm{Ni}$ terhadap resistivitas (Jones, 1988).

4. Perhitungan Permitivitas Relatif (K) Lapisan Tipis $\mathrm{ZnS}$ dan $\mathrm{ZnS}: \mathrm{Mn}$
Untuk menentukan konstante dielektrik/permitivitas relatif bahan dielektrik lapisan tipis $\mathrm{ZnS}$ dan ZnS:Mn dapat dihitung dengan menggunakan persamaan: $\mathrm{K}=\mathrm{Cd} / \varepsilon_{\mathrm{o}} \mathrm{A}$ dengan luas lapisan kontak(elektroda) A adalah $7,85 x$ $10^{-5} \mathrm{~m}^{2}$

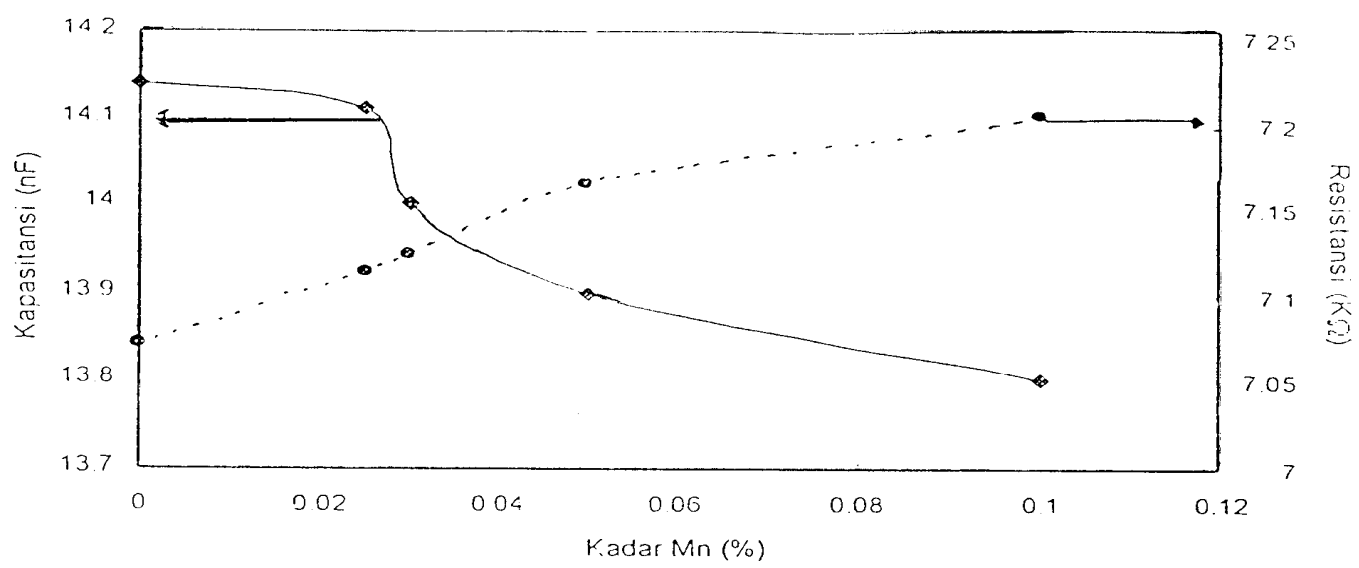

Gambar 2. Hubungan antara kapasitansi dan resistansi dengan kadar Mn yang bervariasi dari lapisan tipis $\mathrm{ZnS}: \mathrm{Mn}$.

Hasil perhitungan konstante dielektrik (K) tanpa dan dengan Mn untuk berbagai variasi kadar Mn dari lapisan tipis tersebut diperlihatkan pada Tabel 1. Dari hasil perhitungan tersebut diperoleh harga rata-rata konstante dielektrik/permitivitas relatf (K) untuk lapisan tipis $\mathrm{Zn}$ sebesar 14,25 dan untuk lapisan tipis $\mathrm{ZnS}: \mathrm{Mn}$ sebesar 14,03 agak berbeda dengan harga 10 dan nilai 10 juga yang diperoleh Abels, et al , (1958).

Beberapa hal dapat menyebabkan diskrepansi ini; pertama karena ketebalan efektif tidak sama dengan ketebalan yang diukur lewat metoda CARIS.
Ketebalan efektif dapat diperkirakan jauh lebih tipis dari keteblan yang terukur, karena adanya difusi atom-atom bahan elektroda Al ke dalam bahan lapisan tipis ZnS:Mn. Kedua, karena luas efektif jauh lebih besar dari luas yang di ukur, karena kontak elektroda pada ZnS:Mn yang terjadi melebar dibandingkan lubang masker. Ketiga, batas antar butir dapat dianggap sebagai kapasitor kecil sejajar kapasitor yang ada. Adanya tambahan kapasitor ini dapat memperbesar nilai kapasitansi yang diukur lewat besarnya impedansi. Untuk memperoleh nilai yang sesuai dengan literatur untuk nilai 
permitivitas relatif kapasitor, amka ketebalan dari lapisan tipis tersebut harus dikoreksi sebesar $70 \%$, sehingga nilai permitivitas relatif kapasitor lapisan tipis $\mathrm{ZnS}$ dan ZnS:Mn mendekati harga 10.

Dengan

bertambah tingginya frekuensi yaitu frekuensi diatas frekuensi $10 \mathrm{Khz}$, maka mulai terlihat pengaruh relaksasi dalam bahan dielektrikum lapisan tipis $\mathrm{ZnS}$ dan $\mathrm{ZnS}: \mathrm{Mn}$ dan tampak adanya puncak relaksasi. Konstante dielektrik/permitivitas relative bukanlah konstan lagi, tetapi merupakan fungsi frekuensi dan oleh sebab itu dengan bertambahnya frekuensi menyebabkan nilai permitivitas relatif semakin kecil.

\section{Simpulan dan Saran}

Dari hasil eksperimen dan pembahasan penelitian ini, maka dapat ditarik kesimpulan sebagai berikut:

1. Pada daerah frekuensi ribuan sampai puluhan ribu Hertz, dapat dikatakan bahwa permitivitas relatif/konstante dielektrik statis $K_{(0)}$ lapisan tipis $\mathrm{ZnS}: \mathrm{Mn}$ bukan merupakan fungsi frekuensi sehingga dapat dianggap sama/konstan seperti $\mathrm{K}_{(0)}=$ 10.

2. Harga Kapasitansi ZnS:Mn bertambah besar dengan semakin berkurangnya kadar Mangan dalam lapisan tipis tersebut.

3. Harga resistansi listrik ZnS:Mn berkurang dengan semakin kecil kadar mangan (Mn) pada lapisan tipis tersebut.
Saran:

1. Untuk penelitian lebih lanjutnya, sebaiknya dapat digunakan jenis material lain yang dapat memperoleh sifat listrik lapisan tipis yang lebih ideal sesuai kebutuhannya dengan memvariasikan ketebalan lapisan tipis.

2. Pada saat pembuatan lapisan tipis, diusahakan sampel yang dibuat merata pada seluruh permukaan agar tidak diperoleh gain-gain/ pulaupulau di dalam lapisan tipis tersebut.

3. Pengukuran impendansi lapisan tipis, sebaiknya, kabel penghubung yang digunakan mempunyai hambatannya yang mendekati nol agar tidak kontaminasi dengan lapisan tipis tersebut.

\section{Daftar Pustaka}

Abeles and J.P. Mathien, Anales de Physique 3, 5 ,(1958), guoted by Ashroft/Mermin, 1976. Solids State Physics. Saunders College HRW, Philadelphia.

Anomimous, 1994. Tim Peneliti Lapisan Tipis, Laporan Penelitian Sifat Listrik dan Struktur Kimiawi Lapisan Ni$\mathrm{Cr}$, Universitas Indonesia, Depok.

Anderson, K.D. Leaver, R.D. Rawlings and J.M. Alexander, 1985. Material Science. Van Nosstrand Reinhold U.K., England.

Bringuier, 1994. Journal Applied Physics. 75, 4291-4310. 
Charreire, D.R. Svoronos, I. Ascone, O. Tolonen, L. Ninisto and M. Leskela, 1993. Journal Electrochem. Soc. 140, 2015.

Charles A. Harper, 1977. Handbook of Component for Electronics. Mc Graw-Hill Mary land.

Charlie Kittel, 1986. Introduction to salid state physics. Jhon Wiley \& Sons, sixth edition. 185-205.

Freeman, K.R Poepelmeir, T.O Mason, R.P.H. Chang and T.J. Marks, 2000. Chemical and thin film stategies for new transparent conducting oxides. MRS. Buletin. Transparent conducting oxides ISSN. 0883-7692. 25.45.

Fuh, R.P. Gallinger and O. Can, 1987. Journal Applied Physics. 65, 1060.

Gordon, 2000. Criteria for choosing transparent conductors. MRS, Bulletin. Transparent conducting oxides, ISSN. 0883-7694. 25.26.

Herbert, 1985. Ceramics Dielektric and Capasitors. Vol. 6, Gordon and Breach Science Publishers, New York.

Higuchi, M. Ushio, Y. Nakanishi and K. Takahashi, 1988. Applied Surface Science. 33-34.

Hozokazu Izumi, Frederick O. Adurodija, Takahiro Kaneyoski, Tsuguo Ishihara, Hideki Yoshioka, Muneyuki Motoyama, 2002. Electrical and structural properties of indium tin oxide films prepared by pulsed laser deposition. Journal Applied Physics 91. 1213-1217.

Jones, D.Y. Waats, 1988. Journal Crystal Growth, 86, 880-884.

Kim, J.S Horwitz. G. Kushto, A. Pique, Z. H. Kafafi, C.M. Gilmore and D.B Chrisey, 2000. Effect of films thickness on the properties of inbdium tin oxide thin films. Journal Applied physics, 88. 60226023.

Lee and C.Y Pueng, 1993. Journal Material Science. 28.

Lewis and D.C. Paine, 2000. Application and processing of transparent conductingoxides. MRS. Buletin. Transparent conducting oxides. ISSN. 7694. 25. 22.

Leonid V. Azaroff, 1970. Introduction to Solids. Tata Mc Geaw-Hill, Publishing Company LTD, Bombay New Delhi.

Maissel, R. Glang, 1970. Handbook of Thin Films Technologi. Mc Graw-Hill Book Co, New York.

Marc Beale, 1993. Phylosophical Magazine B. 68, 573-594.

Okamoto, T. Yoshimi, K. Nakamura. T Kabayashi, S. Sato and S. Miura, 1989. Journal Applied Physics. 28, 1378-1384. 
Ono, 1993. Encyclopedia of Applied Physics. 5, 304.

Roberts and D.S. Campell, J. Brit, IRE, 22, 281, 961, guoted by P.J. Harrup, 1970. Handbook of Thin Films Technologi. Edited by L.I./ Maisell and R. Glang. Mc Graw-Hill Book Co., New ork.

Somarjai, 1972. Principles of Surface Chemestry. Prestice-Hall Inc, New Jersey.
Van Vlack, 1959. Elementary of Material Science. Addison Wesley, London.

Xian, P. Benalloud, C. Bertho, and J.Benoit, 1994. Thin Solids Films. 248, 193-198.

Zeinert, P. Benallout. J. Benoit, C. Barthou, J Drey hsig, andH.E. Gumlich, 1992. Journal Applied Physics. 71, 28552862. 